WTC 2004

\title{
New development of waterjet technology for tunnel excavation purposes
}

\author{
Fu-Shu Jeng ${ }^{\text {a,*}}$, Tsang-Hwei Huang ${ }^{\text {a }}$, Stefan Hilmersson ${ }^{b}$ \\ a Department of Civil Engineering, National Taiwan University, Taipei, Taiwan \\ ${ }^{\mathrm{b}}$ Aquajet systems AB, Sweden
}

The results of research regarding the use of waterjet for tunneling purpose, i.e. rock excavation, indicate that high power waterjet, instead of high pressure waterjet is more adequate for excavating rocks. A series of laboratory and field experiments has been conducted by applying waterjet to cut various types of rocks, including sandstone, metasandstone, schist, andesite, marble, granite, etc., in Taiwan and in Sweden.

The experimental results revealed that the conventional high pressure waterjet (with pressures up to $420 \mathrm{MPa}$ and a working rate up to $30 \mathrm{~kW}$ ) for cutting purposes has a very limited cutting depth (about $15 \mathrm{~cm}$ ); hence it can not be use for tunneling purposes, in which a cutting depth of $1 \sim 4 \mathrm{~m}$ meters is desired. Therefore, the waterjet with somewhat lower pressure (about $150 \mathrm{MPa}$ ) but much larger working rate (more than $300 \mathrm{~kW}$ ) used for hydro-demolition was considered for tunneling purposes. Further experiments indicated that this hydro-demolition waterjet is capable of cutting moderate to weak rocks with a depth of $1 \sim 2 \mathrm{~m}$, which is acceptable for tunneling purposes. In general, when the rock is fractured by waterjet, the phenomena including penetration hole, radial cracks and surface chipping can be observed. When the rock is soft, waterjet can penetrate the rock with minor surface chipping and hardly any radial cracks, in which a deep hole, with a depth exceeding $30 \mathrm{~cm}$, is produced by waterjet. When the rock is strong, metasandstone for example, the waterjet cannot efficiently penetrate the rock (with a penetration depth less than $10 \mathrm{~cm}$ ) and induces large pieces of surface chipping. However, for strong rocks (with uniaxial compressive strength exceeding 70 $\mathrm{MPa}$ ) tested in field, the penetration depths can be as shallow as $12 \mathrm{~cm}$, which needs to be further improved.

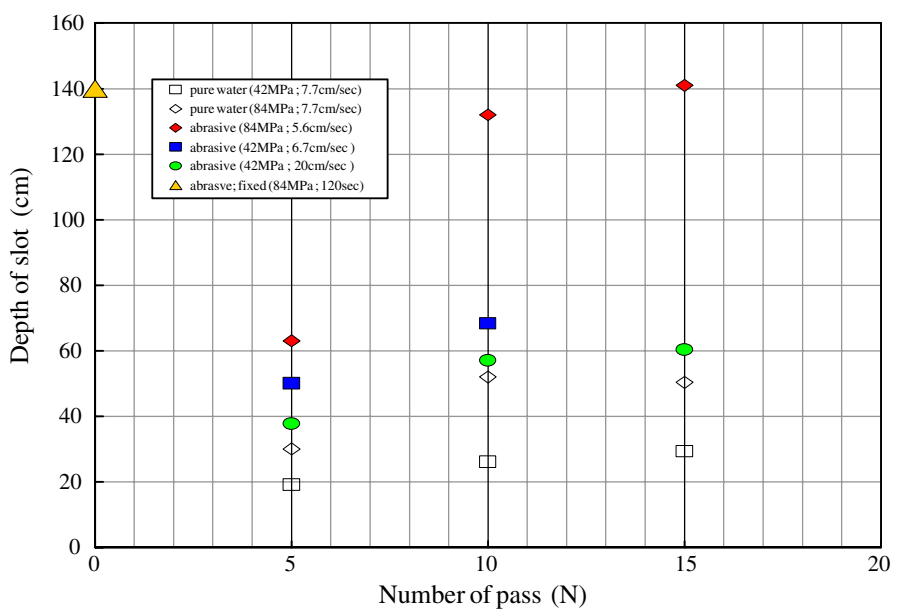

\footnotetext{
${ }^{*}$ Corresponding author. Tel.: +886-2-2363-0530; fax: +886-2-2364-5734.

E-mail address: fsjeng@ntu.edu.tw (F.-S. Jeng).
} 
Therefore, more efforts have been employed in developing a waterjet capable of cutting hard rock with a depth exceeding $1 \mathrm{~m}$. Accordingly, abrasive was added into the high power demolition-typed waterjet to form an abrasive waterjet. The results are exciting; the developed abrasive waterjet can cut hard rock with a depth of $1.5 \mathrm{~m}$ with a fairly fast speed of $2 \sim 4 \mathrm{~m}$ per minute. It was also found that an increase of adding rate of abrasives was helpful in improving the ability of damage of waterjet; however, too high adding rate would result in interference with the jet and led to a decreasing cutting rate. Overall, the combined usage of high power waterjet and abrasive waterjet shows versatile applicability in rock excavation, which can be adopted in tunneling engineering and slope engineering.

Keywords: Rock excavation; Waterjet; Abrasive 